\title{
Ultrasound-Assisted, Base-Catalyzed, Homogeneous Reaction for Ferulic Acid Production from $\gamma$-Oryzanol
}

\author{
Hoa Thi Truong $\mathbb{D}^{1},{ }^{1}$ Manh Van Do, ${ }^{1}$ Long Duc Huynh, ${ }^{1}$ Linh Thi Nguyen, ${ }^{1}$ Anh Tuan Do, ${ }^{1}$ \\ Thao Thanh Xuan Le, ${ }^{1}$ Hung Phuoc Duong, ${ }^{2}$ Norimichi Takenaka, ${ }^{3}$ \\ Kiyoshi Imamura, ${ }^{4}$ and Yasuaki Maeda ${ }^{4}$
}

${ }^{1}$ Danang Environmental Technology Center, Institute of Environmental Technology, Vietnam Academy of Science and Technology, Tran Dai Nghia Road, Ngu Hanh Son Dist., Da Nang 550000, Vietnam

${ }^{2}$ International Cooperation Department, Ministry of Natural Resources and Environment, 10 Ton That Thuyet St., Hanoi 100000, Vietnam

${ }^{3}$ Department of Applied Chemistry, Graduate School of Engineering, Osaka Prefecture University, 1-1 Gakuen-cho, Nakaku, Sakai, Osaka 599-8531, Japan

${ }^{4}$ Research Organization for University-Community Collaborations, Osaka Prefecture University, 1-1 Gakuen-cho, Nakaku, Sakai, Osaka 599-8531, Japan

Correspondence should be addressed to Hoa Thi Truong; hoa.danetc@gmail.com

Received 8 September 2017; Accepted 11 April 2018; Published 13 May 2018

Academic Editor: Sevgi Kolaylı

Copyright (c) 2018 Hoa Thi Truong et al. This is an open access article distributed under the Creative Commons Attribution License, which permits unrestricted use, distribution, and reproduction in any medium, provided the original work is properly cited.

\begin{abstract}
A method for producing ferulic acid by ultrasound-assisted, homogeneous, base-catalyzed hydrolysis of $\gamma$-oryzanol was developed. Experiments were conducted using various reaction temperatures and ratios of $\gamma$-oryzanol to base catalyst in both homogeneous and heterogeneous systems. The reaction performed without ultrasound under the homogeneous conditions of potassium hydroxide/ $\gamma$-oryzanol ratio (wt/wt) $20: 1$ and $75^{\circ} \mathrm{C}$ gave a ferulic acid yield of $83.3 \%$ in $3 \mathrm{~h}$. Acceleration of the homogeneous reaction using ultrasound irradiation at 20 (horn type) and $200 \mathrm{kHz}$ (planar type) was explored by evaluating the kinetic parameters. At $30^{\circ} \mathrm{C}$, the ratios of ultrasonic irradiation at low $(20 \mathrm{kHz}, 50 \mathrm{~W})$ and high $(200 \mathrm{kHz}, 50 \mathrm{~W})$ frequencies versus those of the heating method increased by 2.0 - and 1.4-fold in comparison with those at $60^{\circ} \mathrm{C}$, respectively. The contribution of ultrasonic irradiation $(50 \mathrm{~W})$ to the hydrolysis reaction decreased with increase of temperature. However, irradiation at $20 \mathrm{kHz}$ and a power of $180 \mathrm{~W}$ gave a $94 \%$ ferulic acid yield at $60^{\circ} \mathrm{C}$ in $3 \mathrm{~h}$. These results indicate that the use of low frequency (horn type and high-power irradiation) enabled yields higher than $90 \%$ to be obtained.
\end{abstract}

\section{Introduction}

Ferulic acid (FA) is one of the most promising biomass of phenolic acid derivatives with its antioxidant properties such as UV protectant in cosmetics, food additive, and being used in various medical applications. FA also helps to prevent cardiovascular disease, diabetes, Alzheimer's disease, and colon cancer [1-8]. Nitrites, usually sodium nitrite, are used in the food industry as preservatives to maintain color and prevent pathogen growth. In acidic conditions in the stomach, nitrites can react with many other compounds to produce nitrosamines, which are known carcinogens. The use of FA to block nitrosamine formation from nitrites has been investigated in the literature [9].

FA can be synthesized by the condensation of vanillin with malonic acid. The reaction gives a high yield of a mixture of trans- and cis-FA [10]; trans-FA, which can be crystallized, is commercially important because of its biological activities. Alkaline hydrolysis has been used to produce FA from natural sources, and various procedures for extraction of FA have been applied depending on the properties of the raw material $[1,11-13]$. FA cannot be extracted directly from their matrix in the rice bran [14] because of existence of conjugated forms and/or its ester 
form of $\gamma$-oryzanol. However, FA can be produced from $\gamma$-oryzanol-containing by-products by hydrolysis reaction, for example, soapstock from rice bran oil processing $[15,16]$.

Ultrasound irradiation has recently been evaluated as an effective method for accelerating hydrolysis reactions [17-27]. However, a few experiments on the hydrolysis of the hydrophobic compounds of $\gamma$-oryzanol consisting of bulky steroid groups and para-orientated hydroxyl group have been conducted. In our previous study, the ultrasound irradiation $(78 \mathrm{kHz}, 130 \mathrm{kHz}, 50 \mathrm{~W}$, and planar type) was explored, and the reaction was accelerated by around $10 \%$ [16] at the temperature of 60 and $75^{\circ} \mathrm{C}$ in comparison with the conventional heating method.

In this study, we examined the ferulic acid production from $\gamma$-oryzanol by various kinds of binary solvent systems: two kinds of homogeneous and one kind of heterogeneous systems. The experiments were performed using various ratios of $\gamma$-oryzanol/base catalyst and reaction temperatures. For accelerating the reaction, ultrasound irradiations of two kinds of frequency, for example, $20 \mathrm{kHz}$ (horn type) and $200 \mathrm{kHz}$ (planar type) with power of $50 \mathrm{~W}$ and $180 \mathrm{~W}$ were applied. The kinetic parameters of ultrasound-assisted homogeneous reaction systems were also estimated.

\section{Materials and Methods}

2.1. Chemicals and Equipment. The purities of trans-FA, $\gamma$-oryzanol, and ethyl ferulate (EF) standards (SigmaAldrich, USA) were over 99\%. Inorganic compounds (potassium hydroxide $(\mathrm{KOH})$, sulfuric acid, and phosphoric acid) and organic reagents and solvents (acetic acid, ethanol, and ethyl acetate) were of analytical grade and purchased from Merck (Germany). Acetonitrile, methanol, and water used as mobile phases were of HPLC grade and were also purchased from Merck.

A solution of $\gamma$-oryzanol $(48 \mathrm{mg} / \mathrm{mL})$ was prepared by dissolving $\gamma$-oryzanol ( $4.8 \mathrm{~g})$ in ethyl acetate $(100 \mathrm{~mL}) . \mathrm{KOH}$ solutions of concentrations 192, 240, 384, and $480 \mathrm{mg} / \mathrm{mL}$ were prepared by dissolving 48,60, 96, or $120 \mathrm{~g}$ of $\mathrm{KOH}$ in water $(250 \mathrm{~mL})$. For comparison, $\mathrm{KOH}$ solutions of concentrations $96,120,192$, and $240 \mathrm{mg} / \mathrm{mL}$, that is, half the concentrations of the aqueous solutions, were prepared in methanol. The mass ratio of $\mathrm{KOH} / \gamma$-oryzanol, denoted by KO, was varied from $8: 1$ to $20: 1$.

A low-frequency $(20 \mathrm{kHz})$ horn-type ultrasonicator (Sonifier 450, Ti horn of diameter $1.1 \mathrm{~cm}$, maximum power 400 W, Branson Co., Tokyo, Japan) and a high-frequency $(200 \mathrm{kHz})$ planar-type ultrasonicator (Kaijo Corporation, Tokyo, Japan) were used to accelerate the hydrolysis reaction. The dissipation powers were 50 and $180 \mathrm{~W}$.

2.2. Hydrolysis of $\gamma$-Oryzanol. In our previous study, the experiment of $\gamma$-oryzanol hydrolysis was evaluated with the initial concentration of $12 \mathrm{mg} / \mathrm{mL}$ of $\gamma$-oryzanol under the reaction temperature of $60-75^{\circ} \mathrm{C}$ to prevent the precipitates in the homogeneous systems [16]. In this study, the initial concentration of $\gamma$-oryzanol was adjusted by $6 \mathrm{mg} / \mathrm{mL}$, and the reaction temperature was varied in the range of $30-75^{\circ} \mathrm{C}$ to avoid precipitation during the reaction.

\subsubsection{Composition of Homogeneous Type A Solvent (Ethyl} Acetate/Water/Ethanol). The homogeneous reaction system designated as Type A was prepared as follows. A $\gamma$-oryzanol solution $(48 \mathrm{mg} / \mathrm{mL}, 4 \mathrm{~mL})$ was added to ethanol $(20 \mathrm{~mL})$ in a $100 \mathrm{~mL}$ glass flask with a screw cap. The flask was placed in a water bath controlled at temperatures from 30 to $75^{\circ} \mathrm{C}$ using a temperature controller (Thermal Robo TR-2A, As One, Osaka, Japan). $\mathrm{KOH}$ solutions of various concentrations $(192,240,384$, and $480 \mathrm{mg} / \mathrm{mL}, 8 \mathrm{~mL})$ were added to the mixture to prepare solutions with $\mathrm{KO}$ ratios of $8,10,16$, and 20. The initial concentration of $\gamma$-oryzanol was $6 \mathrm{mg} / \mathrm{mL}$. After closing the flask with the cap, the mixture was shaken by hand to form a uniform dispersion and then held in the water bath, without stirring or acceleration by ultrasound irradiation (hereinafter called the heating method). The reaction temperature was varied from 30 to $75^{\circ} \mathrm{C}$. An aliquot $(100 \mu \mathrm{L})$ was removed every $30 \mathrm{~min}$, and the reaction products and amount of $\gamma$-oryzanol were determined using HPLC. The reaction was monitored for $4 \mathrm{~h}$.

2.2.2. Composition of Homogeneous Type B Solvent (Ethyl Acetate/Methanol/Ethanol). The procedure for preparation of the homogeneous reaction system designated as Type B was as follows. A $\gamma$-oryzanol solution $(48 \mathrm{mg} / \mathrm{mL}, 4 \mathrm{~mL})$ was added to ethanol $(12 \mathrm{~mL})$ in a $100 \mathrm{~mL}$ glass flask with a screw cap. Methanolic $\mathrm{KOH}$ solutions of concentrations 96, 120, 192 , and $240 \mathrm{mg} / \mathrm{mL}(16 \mathrm{~mL})$, corresponding to $\mathrm{KO}$ ratios of $8,10,16$, and 20 , were added. The subsequent process was the same as that described in Section 2.2.1.

\subsubsection{Composition of Heterogeneous Type C Solvent (Ethyl} Acetate/Water). The heterogeneous system designated as Type $\mathrm{C}$ consisted of a $\gamma$-oryzanol in ethyl acetate solution and aqueous $\mathrm{KOH}$ solution. The preparation procedure was the same as that described in Section 2.2.1, except for the addition of ethanol as a cosolvent and the volume of ethyl acetate $(20 \mathrm{~mL})$.

2.3. Hydrolysis Using Ultrasound Irradiation. The effects of ultrasound irradiation on the reaction were examined using a homogeneous aqueous organic phase (Type A) at 30 to $60^{\circ} \mathrm{C}$. The procedure was as follows. A solution of $\gamma$-oryzanol $(48 \mathrm{mg} / \mathrm{mL}, 16 \mathrm{~mL})$ in ethyl acetate was added to ethanol $(80 \mathrm{~mL})$ in a $250 \mathrm{~mL}$ glass flask with a screw cap. This flask was placed in a water bath at a specified temperature, controlled by a Robo TR-2A thermal controller (As One Co., Osaka, Japan), and then $\mathrm{KOH}$ solution $(32 \mathrm{~mL}$ ) was quickly added. The flask was shaken by hand. For low-frequency $(20 \mathrm{kHz})$ irradiation with a horn-type sonicator, the horn tip was immersed in the middle of the mixed solution. The flask was covered with paraffin film, and the dissipation power was 50 or $180 \mathrm{~W}$. The reaction products were monitored for $4 \mathrm{~h}$. For high-frequency $(200 \mathrm{kHz})$ irradiation with a planartype sonicator, the flask containing the reaction mixture was 


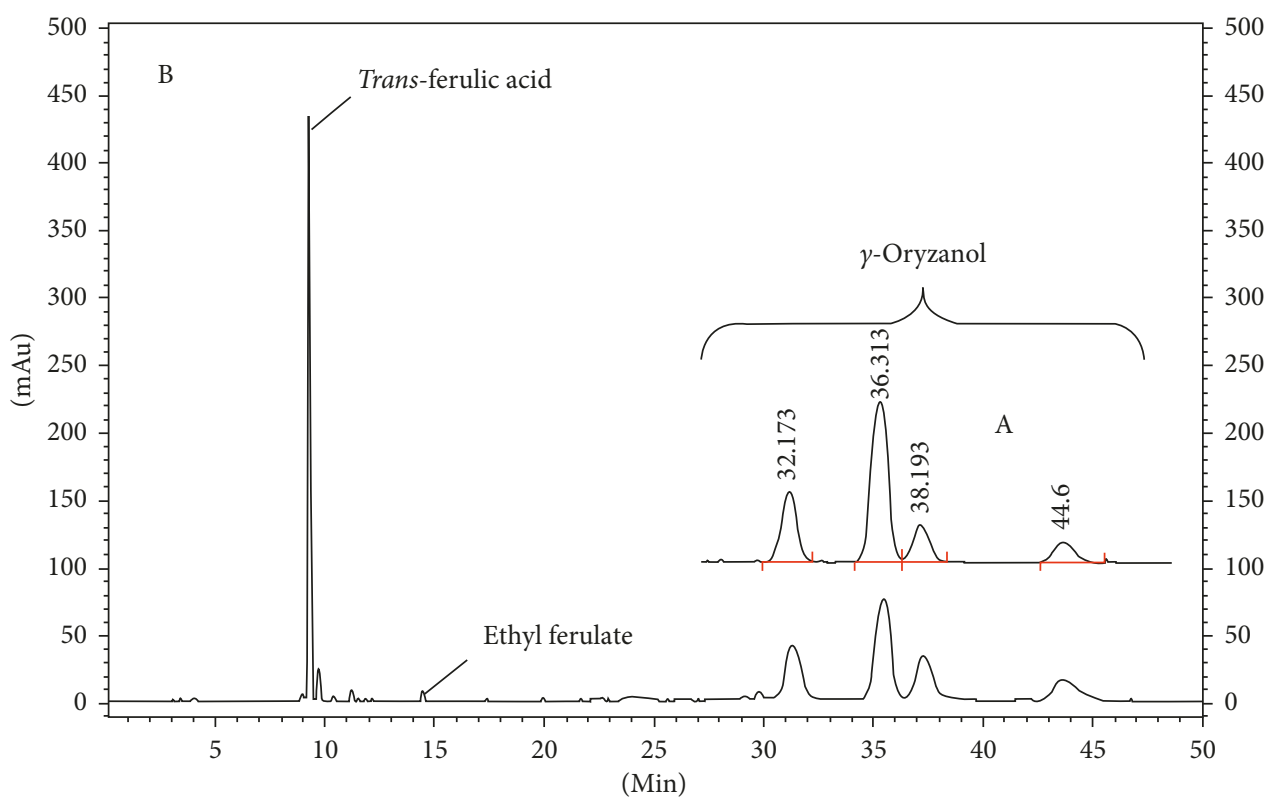

Figure 1: HPLC chromatogram ( $\left.\mathrm{UV}_{235 \mathrm{~nm}}\right)$ of $\gamma$-oryzanol standards (A) and hydrolysis products (B).

closed with the screw cap and placed on the transducer, and then irradiation was started.

2.4. HPLC Determination of $\gamma$-Oryzanol, FA, and EF. FA, $\gamma$-oryzanol, and EF were determined as follows: Concentrated acetic acid $(100 \mu \mathrm{L})$ was added to the reaction mixture $(100 \mu \mathrm{L})$ to terminate the reaction. The mixed solution was diluted to $1.5 \mathrm{~mL}$ with ethanol, and an aliquot $(10 \mu \mathrm{L})$ was subjected to high-performance liquid chromatograph (HPLC) analysis. The GL-7480 HPLC system (GL Science Inc., Tokyo, Japan) was equipped with a photodiode array detector (GL-7452, GL Science Inc., Tokyo, Japan) and an autosampler (GL-7420, GL Science Inc., Tokyo, Japan). A reverse-phase Inertsil ODS-3 $\mathrm{C}_{18}(4.6 \mathrm{~mm} \times 250 \mathrm{~mm}$, film thickness $5 \mu \mathrm{m}$; GL Science, Tokyo, Japan) column was used. The analytical parameters were described in our previous study [16]. The FA, EF, and $\gamma$-oryzanol contents were determined using a direct calibration method with a coefficient of determination $\left(R^{2}\right)$ greater than 0.9990 in the concentration ranges of 10-250, 10-100, and $100-1200 \mu \mathrm{g} / \mathrm{mL}$, respectively. Because $\gamma$-oryzanol is a mixture of four main components, the calibration curve for $\gamma$-oryzanol was based on the sum of the areas of the four peaks versus the concentration of FA. The yield of FA (\%) and that of $\mathrm{EF}(\%)$ were calculated as

$$
\text { yield of FA }(\mathrm{EF})=\frac{\mathrm{FAc}(\mathrm{EFc})}{\mathrm{FAc}+\mathrm{EFc}+\mathrm{Orc}} \times 100 \% \text {, }
$$

where FAc is the molar concentration of FA, EFc is the molar concentration of EF, and Orc is the molar concentration of $\gamma$-oryzanol. The obtained values were the averages of triplicate measurements.

2.5. Kinetic Calculation. The base-catalyzed hydrolysis of ester is expressed as the second-order reaction as the reaction rate depends on both concentrations of ester and hydroxide ion as follows:

$$
\text { rate }=k\left[\mathrm{OH}^{-}\right][\text {ester }]
$$

Usually, large amount of reagent $\left[\mathrm{OH}^{-}\right]$versus ester is added to the reaction system, and then the rate can be abbreviated and converted to pseudo-first-order reaction by dependency of ester concentration [28] as follows:

$$
k t=-\ln \left(\frac{C_{t}}{C_{0}}\right)
$$

where $C_{0}$ is the initial concentration $(\mathrm{mg} / \mathrm{mL})$ of $\gamma$-oryzanol and $C_{t}$ is the concentration of $\gamma$-oryzanol $(\mathrm{mg} / \mathrm{mL})$ at reaction time $t(\mathrm{~min})$. The activation energy $\left(E_{\mathrm{a}}, \mathrm{J} / \mathrm{mol}\right)$ for $\gamma$-oryzanol hydrolysis was estimated using the following equations:

$$
\begin{aligned}
k & =A \exp \left(\frac{-E_{\mathrm{a}}}{R T}\right), \\
\ln k & =\frac{-E_{\mathrm{a}}}{R T}+\ln A,
\end{aligned}
$$

where $k$ is the rate constant, $T$ is the Kelvin temperature, $R$ is the molar gas constant $\left(8.3415 \times 10^{-3} \mathrm{~kJ} /(\mathrm{mol} / \mathrm{K})\right)$, and $A$ is the pre-exponential factor.

\section{Results and Discussion}

3.1. HPLC Analysis of $\gamma$-Oryzanol, FA, and EF. The HPLC chromatogram (photodiode array detection at $325 \mathrm{~nm}$ ) of $\gamma$-oryzanol and its hydrolysis products of homogeneous system of Type A is shown in Figure 1. The peaks eluted in the range of $32-45 \mathrm{~min}$ were assigned to $\gamma$-oryzanol by comparing with authentic standards (Figure 1(a)). As hydrolysis proceeded, peaks for trans-FA and the intermediates ethyl ferulate (EF) appeared at retention times of 9.3 and $14.4 \mathrm{~min}$, respectively (Figure 1(b)). 
TABLE 1: The yields of ferulic acid from hydrolysis of $\gamma$-oryzanol by heterogeneous and homogeneous systems with assistance of ultrasonic irradiation.

\begin{tabular}{|c|c|c|c|c|c|c|c|c|}
\hline \multirow{3}{*}{$\begin{array}{l}\text { Type of } \\
\text { reaction }\end{array}$} & \multirow{3}{*}{$\begin{array}{c}\gamma \text {-oryzanol* } \\
(\mathrm{mg} / \mathrm{mL})\end{array}$} & \multirow{3}{*}{$\begin{array}{l}\mathrm{KO}^{1} \\
\text { ratio }\end{array}$} & \multirow{3}{*}{$\begin{array}{l}\text { Temp. } \\
\left({ }^{\circ} \mathrm{C}\right)\end{array}$} & \multicolumn{5}{|c|}{ Yield of ferulic acid (\%) } \\
\hline & & & & \multirow{2}{*}{$\begin{array}{l}\text { Heating } \\
\text { method }\end{array}$} & \multicolumn{2}{|c|}{ US $(20 \mathrm{kHz})^{3}$} & \multicolumn{2}{|c|}{ US $(200 \mathrm{kHz})^{4}$} \\
\hline & & & & & $50 \mathrm{~W}$ & $180 \mathrm{~W}$ & $50 \mathrm{~W}$ & $180 \mathrm{~W}$ \\
\hline \multicolumn{9}{|c|}{ Homogeneous condition (ethyl acetate $/ \mathrm{H}_{2} \mathrm{O} /$ cosolvent: ethanol) } \\
\hline \multirow{8}{*}{ Type A } & 6 & 8 & 75 & 37.3 & - & - & - & - \\
\hline & 6 & 10 & 75 & 56.5 & - & - & - & - \\
\hline & 6 & 16 & 75 & 81.4 & - & - & - & - \\
\hline & 6 & 20 & 75 & 83.3 & - & - & - & - \\
\hline & 6 & 20 & 60 & 62.3 & 65.8 & 94.0 & 63.1 & 63.8 \\
\hline & 6 & 20 & 50 & 45.8 & 52.2 & - & 52.0 & - \\
\hline & 6 & 20 & 40 & 25.2 & 42.1 & - & 33.7 & - \\
\hline & 6 & 20 & 30 & 18.8 & 34.2 & - & 26.1 & - \\
\hline \multicolumn{9}{|c|}{ Homogeneous condition (ethyl acetate/methanol/cosolvent: ethanol) } \\
\hline \multirow{4}{*}{ Type B } & 6 & 8 & 75 & 0.7 & - & - & - & - \\
\hline & 6 & 10 & 75 & 0.9 & - & - & - & - \\
\hline & 6 & 16 & 75 & 1.1 & - & - & - & - \\
\hline & 6 & 20 & 75 & 1.8 & - & - & - & - \\
\hline \multicolumn{9}{|c|}{ Heterogeneous condition (ethyl acetate $/ \mathrm{H}_{2} \mathrm{O}$ ) } \\
\hline \multirow{2}{*}{ Type C } & 6 & 10 & 75 & 8.9 & - & - & - & - \\
\hline & 6 & 20 & 75 & 12.3 & - & - & - & - \\
\hline
\end{tabular}

${ }^{*}$ Initial concentration of $\gamma$-oryzanol in ethyl acetate. ${ }^{1}$ Mass ratio of $\mathrm{KOH} / \gamma$-oryzanol (wt/wt). ${ }^{2}$ Reaction temperature. ${ }^{*}$ Ultrasound-assisted method with $20 \mathrm{kHz} .{ }^{4}$ Ultrasound-assisted method with $200 \mathrm{kHz}$. Reaction time: $180 \mathrm{~min}$.

\subsection{Hydrolyses Using Homogeneous and Heterogeneous} Systems. Two homogeneous solvent systems, that is, binary solvents consisting of ethanol/ethyl acetate combined with water (Type A) or methanol (Type B), and heterogeneous one (Type $\mathrm{C}, \mathrm{KOH} /$ water) were investigated. The yields of FA were evaluated using various $\mathrm{KO}$ ratios and reaction temperatures as shown in Table 1 . Under aqueous heterogeneous conditions (Type $\mathrm{C}$ ), the maximum yield of FA was $12.3 \%$ even at $75^{\circ} \mathrm{C}$. As in the case of esters containing acidic protons, such as methyl $p$-hydroxybenzoate and methyl salicylate, hydrolysis was sluggish because of the formation of stable anions [29]. $\gamma$-oryzanol contains an acidic proton on the para-substituted hydroxyl group of an aromatic skeleton. Furthermore, the alcoholic portions of $\gamma$-oryzanol consist of bulky steroidal groups, which could prevent reactant molecules attacking $\gamma$-oryzanol. Hydrolysis, therefore, hardly occurred in the Type $\mathrm{C}$ solvent system.

The yields of FA obtained using the Type A system contained with solvent of water were in the range of 37.3-83.3\%, but the yields obtained using the Type B system contained with solvent of methanol were only $0.7-1.8 \%$, and none of peaks corresponding to ferulic acid esters were observed. Hydrolysis and/or transesterification proceed rapidly under homogeneous conditions [30]. However, these results indicate that the presence of water as a solvent in the reaction system is important in the hydrolysis reaction. Hydrolysis is an equilibrium reaction; therefore, the FA produced dissolved in water as the potassium salt, and then the forward reaction proceeded to form FA.

The yields of FA using Type A were investigated by varying the reaction temperature from 30 to $75^{\circ} \mathrm{C}$ and the $\mathrm{KO}$ ratio from 8 to 20 at $75^{\circ} \mathrm{C}$. The FA yield increased with increasing reaction temperature and $\mathrm{KO}$ ratios. When the $\mathrm{KO}$ ratio was greater than 16 , the FA yield reached greater than $80 \%$ at $75^{\circ} \mathrm{C}$ in $3 \mathrm{~h}$ (Table 1). Experimentally, a KO ratio of 20 (A20) was the maximum value for maintaining homogeneous conditions of system, and then, the FA yield of $83.3 \%$ was obtained with the initial $\gamma$-oryzanol concentration of $6 \mathrm{mg} / \mathrm{mL}$ and the $\mathrm{KO}$ ratio of $20: 1$ by the heating method. The reaction temperature was lower, and the reaction time was half in comparison with those using the heterogeneous conventional method reported by Taniguchi et al. [15].

3.3. EF Formation. The time dependences of the EF yields from hydrolysis of $\gamma$-oryzanol in a homogeneous aqueous system (A20) at $50^{\circ} \mathrm{C}$ are shown in Figure 2. The yield of $\mathrm{EF}$, which is an intermediate in $\gamma$-oryzanol transesterification, increased rapidly, reached a maximum in less than $60 \mathrm{~min}$, and then decreased. These results indicate simultaneous transesterification and hydrolysis when both water and ethanol solvent are present. Ultrasound irradiation of 20 and $200 \mathrm{kHz}(50 \mathrm{~W})$ accelerated the reactions compared with the heating method. The intermediate of EF was hydrolyzed to FA, and its content was less than $3 \%$ in $3 \mathrm{~h}$.

3.4. Effect of Ultrasound Irradiation. The effect of ultrasound irradiation on the hydrolysis of $\gamma$-oryzanol was investigated using low-frequency (horn type, $20 \mathrm{kHz}$ ) and highfrequency (planar type, $200 \mathrm{kHz}$ ) ultrasonicators. The experiments were conducted by ultrasonic power of $50 \mathrm{~W}$ at temperature from 30 to $60^{\circ} \mathrm{C}$. The results for $20 \mathrm{kHz}$ irradiation and those for $200 \mathrm{kHz}$ in comparison with the 


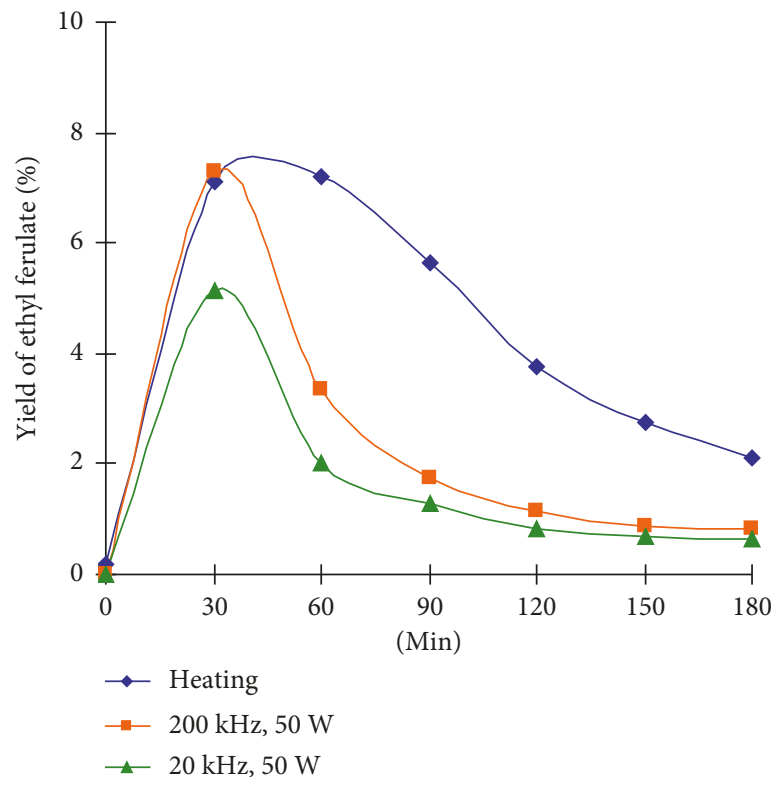

Figure 2: Behavior of ethyl ferulate produced as an intermediate under hydrolysis of $\gamma$-oryzanol by the heating method and ultrasonic irradiation of $20 \mathrm{kHz}$ and $200 \mathrm{kHz}$ with power of $50 \mathrm{~W}$ at $50^{\circ} \mathrm{C}$. Reaction conditions: initial concentration of $\gamma$-oryzanol of $6 \mathrm{mg} / \mathrm{mL}, \mathrm{KO}$ ratio of 20:1 (wt/wt), and homogeneous system of Type A (ethyl acetate/ $\mathrm{H}_{2} \mathrm{O} / \mathrm{ethanol}$ ) (A20).

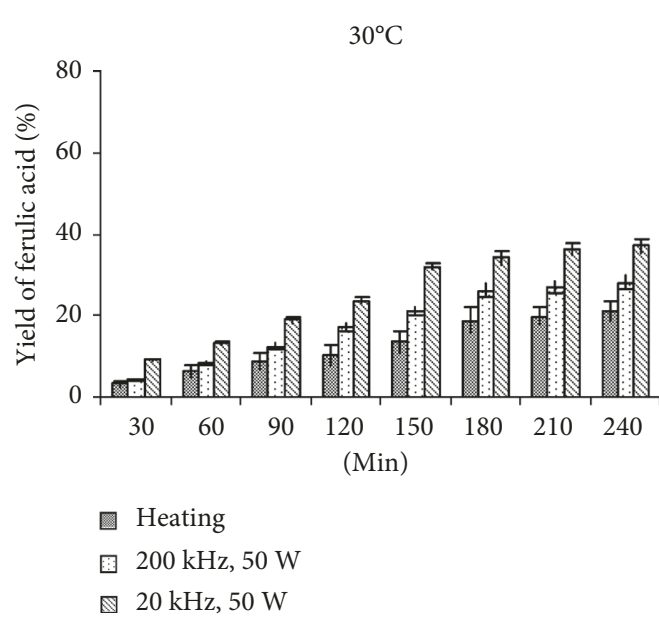

(a)

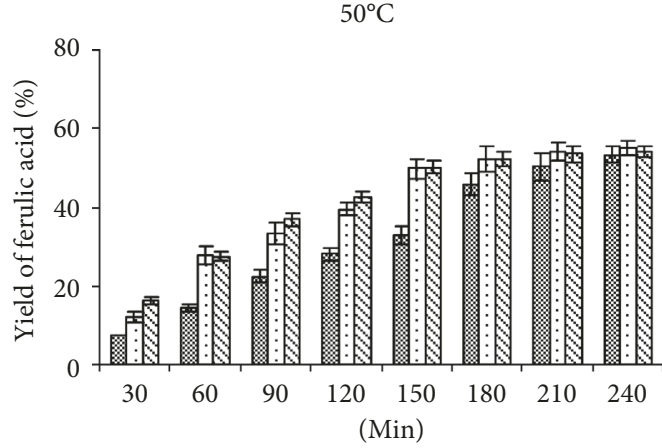

$\square$ Heating
$\square 200 \mathrm{kHz}, 50 \mathrm{~W}$

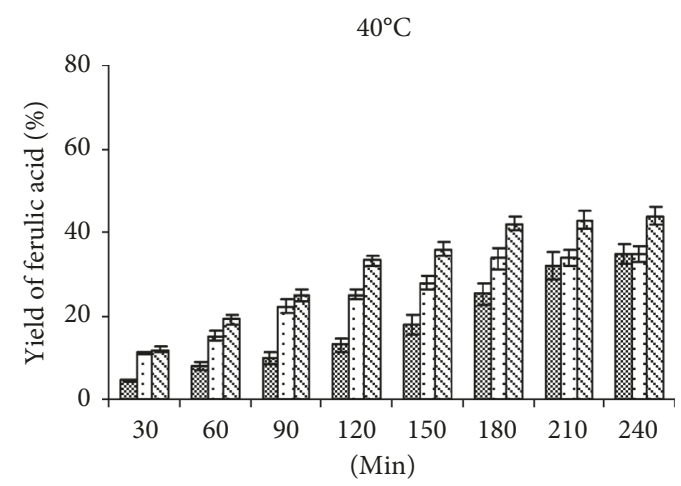

$\square$ Heating

$200 \mathrm{kHz}, 50 \mathrm{~W}$

ه $20 \mathrm{kHz}, 50 \mathrm{~W}$

(b)

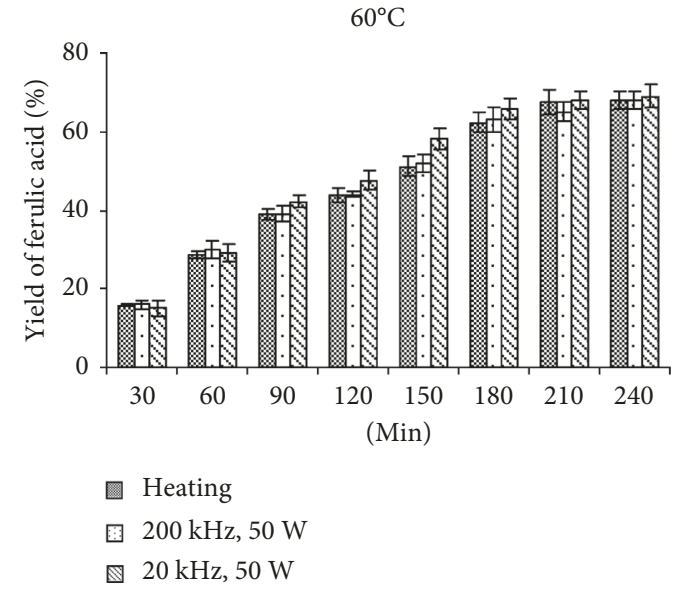

(d)

FIgURE 3: The yields of ferulic acid obtained by the heating method and the ultrasound-assisted method ( 20 and $200 \mathrm{kHz}, 50 \mathrm{~W})$ by varying reaction temperature from 30 to $60^{\circ} \mathrm{C}$ (A20). 


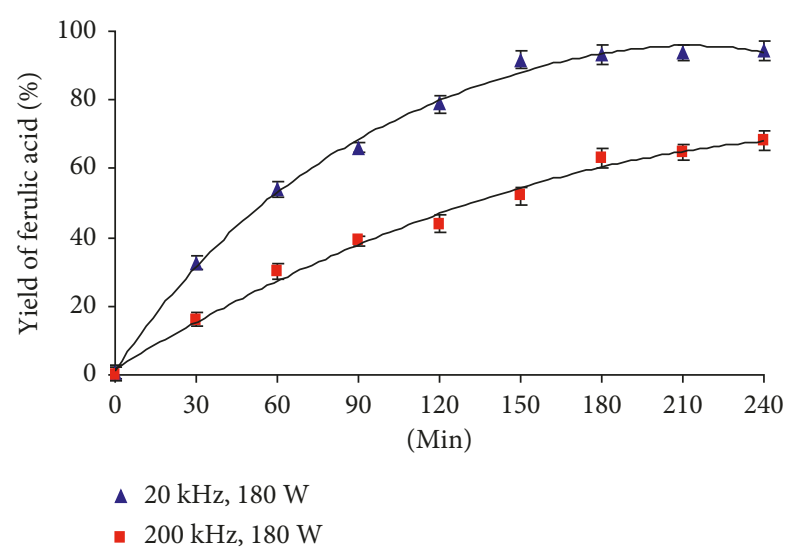

FIGURE 4: The yields of ferulic acid obtained by the ultrasound frequencies of 20 and $200 \mathrm{kHz}$ at power of $180 \mathrm{~W}$ (A20).

heating method are shown in Figure 3. With increasing reaction temperature and reaction time, the yield of FA increased when either $20 \mathrm{kHz}$ or $200 \mathrm{kHz}$ irradiation was used. FA yields of $63-65 \%$ were obtained using $20 \mathrm{kHz}$ or $200 \mathrm{kHz}$ irradiation at $60^{\circ} \mathrm{C}$ for $3 \mathrm{~h}$ with a power of $50 \mathrm{~W}$. By $20 \mathrm{kHz}$ irradiation with a high power of $180 \mathrm{~W}$, greater than $90 \%$ yield of FA was obtained, while by $200 \mathrm{kHz}$ irradiation with the power of $180 \mathrm{~W}$, the yield was $63.8 \%$ (Figure 4 ). The cavitation bubble size is inversely proportional to the frequency [31]; therefore, larger bubbles were produced at $20 \mathrm{kHz}$. These promoted the hydrolysis reaction more powerfully than did the smaller bubbles produced at $200 \mathrm{kHz}$. This is because large bubbles expand and collapse violently that helps to accelerate the reaction.

3.5. Activation Energy of $\gamma$-Oryzanol Hydrolysis. The kinetic parameters for alkaline hydrolysis of $\gamma$-oryzanol (A20) using the heating method and the ultrasonic irradiation methods at 20 and $200 \mathrm{kHz}(50 \mathrm{~W})$ were evaluated. As discussed in Section 2.5, the activation energies were estimated by plotting $\ln k$ versus $1 / T$ (5) using the $k$ values calculated using (3). The linear regression curves and $R^{2}$ values obtained for different methods are shown in Figure 5. The linear relationships between $\ln k$ and $1 / T$ were $y=-5248 x$ $+10.49\left(R^{2}: 0.9878\right)$ for the heating method, $y=-3144 x$ $+4.280\left(R^{2}: 0.9889\right)$ for $20 \mathrm{kHz}$ irradiation, and $y=-4205 x$ $+7.450\left(R^{2}: 0.9828\right)$ for $200 \mathrm{kHz}$ irradiation. These linear correlations show that alkaline hydrolysis of $\gamma$-oryzanol is a pseudo-first-order reaction.

The estimated activation energies $\left(E_{\mathrm{a}}, \mathrm{J} / \mathrm{mol}\right)$ and rate constants are listed in Table 2. The activation energies for $\gamma$-oryzanol hydrolysis using the heating method, $20 \mathrm{kHz}$ irradiation, and $200 \mathrm{kHz}$ irradiation are 43.6, 26.1, and $34.9 \mathrm{~kJ} / \mathrm{mol}$, respectively. These results indicate that ultrasonic irradiation reduced the hydrolysis activation energy, and the lower frequency reduced it more effectively. Acoustic cavitation during sonolysis enhances mass transfer and the diffusion of chemical species and therefore increases the reaction rate $[32,33]$.

The rate constants at $30,40,50$, and $60^{\circ} \mathrm{C}$ for the heating method $\left(k_{\text {heat }}\right)$, irradiation at $20 \mathrm{kHz}\left(k_{\text {sonic20 }}\right)$, and irradiation at $200 \mathrm{kHz}\left(k_{\text {sonic200 }}\right)$, and their ratios of $k_{\text {sonic20 }} / k_{\text {heat }}$ and $k_{\text {sonic200 }} / k_{\text {heat }}$ are summarized in Table 2 . The ratios can be used to evaluate the contribution of ultrasound irradiation. The ratios increased with decreasing reaction temperature. At $30^{\circ} \mathrm{C}$, the ratios of ultrasonic irradiation at low $(20 \mathrm{kHz})$ and high $(200 \mathrm{kHz})$ frequencies versus those of the heating method increased by 2.0 - and 1.4-fold in comparison with those at $60^{\circ} \mathrm{C}$, respectively. Furthermore, the contribution of ultrasonic irradiation to the hydrolysis reaction became decreasing with increase of temperature, as the averaged rate constant among three methods was $5.64 \pm 0.28 \times 10^{4} \mathrm{~min}^{-1}$ at $60^{\circ} \mathrm{C}$. These inverse relationships between the ratios of the rate constants and the reaction temperatures are related to the solvent vapor pressure [25]. Cavitation occurs easily at low temperatures [31]. As the solvent temperature increases, its vapor pressure rises, and the solvent vapor fills the cavitation bubbles. The bubbles then tend to collapse less violently; that is, the sonication effect becomes less intense with increasing temperature. The effect of sonication on the reaction therefore depends on a combination of the reaction temperature and cavitation at a given frequency and power.

\section{Conclusions}

The alkaline hydrolysis of $\gamma$-oryzanol was investigated using two homogeneous reaction systems (Type A and B) and a heterogeneous one (Type $\mathrm{C}$ ). In the experiments, the $\mathrm{KO}$ ratios $(\mathrm{KOH} / \gamma$-oryzanol (wt/wt)) and reaction temperatures were varied, and ultrasonic irradiations at $20 \mathrm{kHz}$ and $200 \mathrm{kHz}$ were used. The reaction was promoted by the homogeneous reaction system with ethanol as a cosolvent (Type A); the water used for a solvent of the $\mathrm{KOH}$ catalyst in the system played an important role for FA production in the hydrolysis reaction. A kinetic study showed that alkaline hydrolysis of $\gamma$-oryzanol is a pseudo-first-order reaction and the activation energies were in the range of $26-44 \mathrm{~kJ} / \mathrm{mol}$. Although the contribution of ultrasonic irradiation to the hydrolysis reaction decreased with increasing temperature, the $\mathrm{FA}$ yield reached $94 \%$ at $60^{\circ} \mathrm{C}$ in $3 \mathrm{~h}$ using low-frequency $(20 \mathrm{kHz})$ irradiation at a high power of $180 \mathrm{~W}$ : this is better than the results achieved using a conventional heating method. This method can be used to produce FA from 


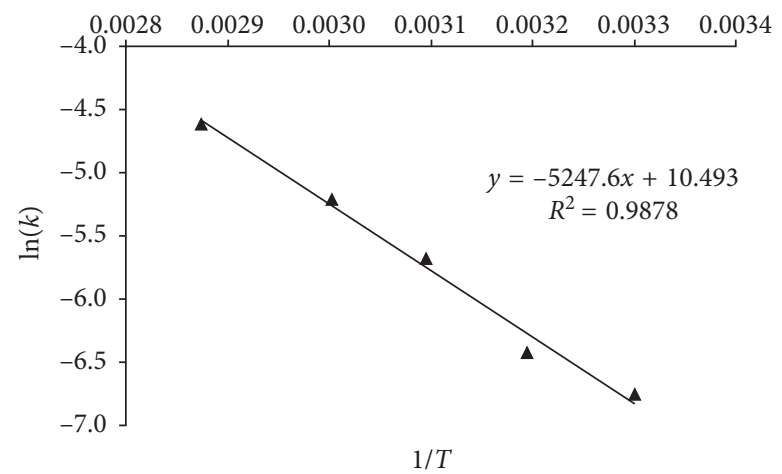

(a)

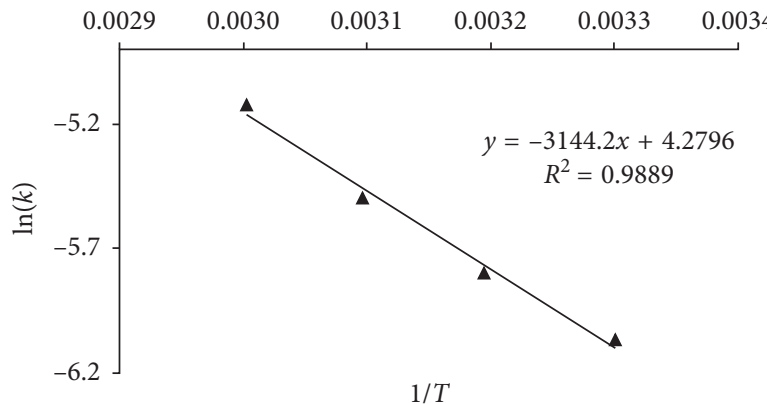

(b)

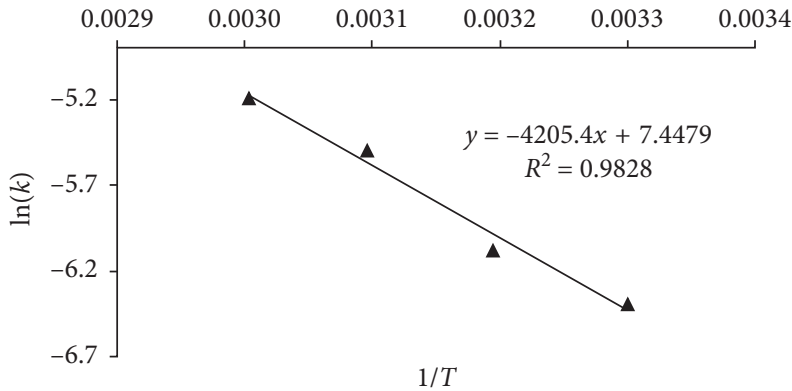

(c)

Figure 5: Arrhenius plot for the hydrolysis of $\gamma$-oryzanol (A20) by the heating method and ultrasonic irradiations. (a) Heating method. (b) $20 \mathrm{kHz}$ ultrasonic irradiation. (c) $200 \mathrm{kHz}$ ultrasonic irradiation.

TABLE 2: The kinetics parameters of $\gamma$-oryzanol hydrolysis obtained by the heating method and the homogeneous system of Type A with assistance of ultrasonic irradiation.

\begin{tabular}{|c|c|c|c|c|c|c|c|}
\hline \multirow{2}{*}{$\begin{array}{l}\text { Method of } \\
\text { hydrolysis }\end{array}$} & \multicolumn{5}{|c|}{$\begin{array}{l}\text { Rate constant } \\
\left(k \times 10^{4}\left(\mathrm{~min}^{-1}\right)\right)\end{array}$} & \multirow{2}{*}{$\begin{array}{c}E_{\mathrm{a}} \\
(\mathrm{kJ} / \mathrm{mol})\end{array}$} & \multirow[t]{2}{*}{$\ln A$} \\
\hline & $30^{\circ} \mathrm{C}$ & $40^{\circ} \mathrm{C}$ & $50^{\circ} \mathrm{C}$ & $60^{\circ} \mathrm{C}$ & $75^{\circ} \mathrm{C}$ & & \\
\hline $\begin{array}{l}\text { Heating method }\left(k_{\text {heat }}\right)^{1} \\
\text { US } 20 \mathrm{kHz}\end{array}$ & 1.16 & 1.61 & 3.40 & 5.42 & 9.92 & 43.6 & 10.493 \\
\hline $\begin{array}{l}\left(k_{\text {sonic } 20}\right)^{2} \\
\left(k_{\text {sonic } 20} / k_{\text {heat }}\right)^{3}\end{array}$ & $\begin{array}{c}2.33 \\
(2.00)\end{array}$ & $\begin{array}{c}3.04 \\
(1.88)\end{array}$ & $\begin{array}{c}4.10 \\
(1.21)\end{array}$ & $\begin{array}{c}5.96 \\
(1.10)\end{array}$ & - & 26.1 & 4.2796 \\
\hline $\begin{array}{l}\text { US } 200 \mathrm{khz} \\
\quad\left(k_{\text {sonic200 }}\right)^{4} \\
\left(k_{\text {sonic200 }} / k_{\text {heat }}\right)^{5}\end{array}$ & $\begin{array}{c}1.67 \\
(1.44)\end{array}$ & $\begin{array}{c}2.29 \\
(1.42)\end{array}$ & $\begin{array}{c}4.08 \\
(1.20)\end{array}$ & $\begin{array}{c}5.54 \\
(1.02)\end{array}$ & - & 34.9 & 7.4479 \\
\hline
\end{tabular}

Reaction system of A20. Type A: consists of ethyl acetate $/ \mathrm{H}_{2} \mathrm{O} /$ ethanol. $^{1}$ Heating method $\left(k_{\text {heat }}\right)$ : rate constant of the heating method. ${ }^{2}$ Ultrasonic irradiation, $20 \mathrm{kHz}, 50 \mathrm{~W}\left(k_{\text {sonic20 }}\right) .{ }^{3}$ In parenthesis: ratio of $k_{\text {sonic20 }}$ versus $k_{\text {heat. }}{ }^{4}$ Ultrasonic irradiation, $20 \mathrm{kHz}, 50 \mathrm{~W}\left(k_{\text {sonic20 }}\right)$. ${ }^{5}$ In parenthesis: ratio of $k_{\text {sonic200 }}$ versus $k_{\text {heat }}$. 
$\gamma$-oryzanol in soapstock from rice bran oil processing at a low temperature and in a short time using low-frequency and high-power irradiation.

\section{Conflicts of Interest}

The authors declare that they have no conflicts of interest.

\section{Acknowledgments}

This research is funded by the Vietnam National Foundation for Science and Technology Development (NAFOSTED) under Grant no. 104.01-2014.57.

\section{References}

[1] S. I. Mussatto, G. Dragone, and I. C. Roberto, "Ferulic and p-coumaric acids extraction by alkaline hydrolysis of brewer's spent grain," Industrial Crops and Products, vol. 25, no. 2, pp. 231-237, 2007.

[2] Y. Sun and W. Wang, "Ultrasonic extraction of ferulic acid from Ligusticum chuanxiong," Journal of the Chinese Institute of Chemical Engineers, vol. 39, no. 6, pp. 653-656, 2008.

[3] N. R. Prasad, S. Ramachandran, K. V. Pugalendi, and V. P. Menon, "Ferulic acid inhibits UV-B-induced oxidative stress in human lymphocytes," Nutrition Research, vol. 27, no. 9, pp. 559-564, 2007.

[4] C. Mancuso and R. Santangelo, "Ferulic acid: pharmacological and toxicological aspects," Food and Chemical Toxicology, vol. 65, pp. 185-195, 2014.

[5] Y. Yan-Ying, Z. Wei, and C. Shu-Wen, "Extraction of ferulic acid and caffeic acid with ionic liquids," Chinese Journal of Analytical Chemistry, vol. 35, no. 12, pp. 1726-1730, 2007.

[6] M. Srinivasan, A. Ram Sudheer, K. Raveendran Pillai, P. Raghu Kumar, P. R. Sudhakaran, and V. P. V.P. Menon, "Influence of ferulic acid on $\gamma$-radiation induced DNA damage, lipid peroxidation and antioxidant status in primary culture of isolated rat hepatocytes," Toxicology, vol. 228, no. 23, pp. 249-258, 2006.

[7] A. Saija, "In vitro and in vivo evaluation of caffeic and ferulic acids as topical photoprotective agents," International Journal of Pharmaceutics, vol. 199, no. 1, pp. 39-47, 2000.

[8] S. Woranuch and R. Yoksan, "Preparation, characterization and antioxidant property of water-soluble ferulic acid grafted chitosan," Carbohydrate Polymers, vol. 96, no. 2, pp. 495-502, 2013.

[9] S. Itagaki, T. Kurokawa, C. Nakata et al., "In vitro and in vivo antioxidant properties of ferulic acid: A comparative study with other natural oxidation inhibitors," Food Chemistry, vol. 114, no. 2, pp. 466-471, 2009.

[10] R. Adams and T. E. Bockstahler, "Preparation and reactions of o-hydroxycinnamic acids and esters," Journal of the American Chemical Society, vol. 74, no. 21, pp. 5346-5348, 1952.

[11] X. Zhu, Y. Cheng, P. Chen et al., "Effect of alkaline and highpressure homogenization on the extraction of phenolic acids from potato peels," Innovative Food Science \& Emerging Technologies, vol. 37, pp. 91-97, 2016.

[12] N. H. M. Salleh, M. Z. M. Daud, D. Arbain, M. S. Ahmad, and K. S. K. Ismail, "Optimization of alkaline hydrolysis of paddy straw for ferulic acid extraction," Industrial Crops and Products, vol. 34, no. 3, pp. 1635-1640, 2011.

[13] P. Torre, B. Aliakbarian, B. Rivas, J. M. Domínguez, and A. Attilio Converti, "Release of ferulic acid from corn cobs by alkaline hydrolysis," Biochemical Engineering Journal, vol. 40, no. 3, pp. 500-506, 2008.

[14] H. T. Truong, P. D. Luu, K. Imamura et al., "Binary solvent extraction of tocols, $\gamma$-oryzanol, and ferulic acid from rice bran using alkaline treatment combined with ultrasonication," Journal of Agricultural and Food Chemistry, vol. 65, no. 24, pp. 4897-4904, 2017.

[15] H. Taniguchi, "Method of manufacturing ferulic acid," Google Patents, 1994.

[16] H. Truong, M. D. Van, L. D. Huynh et al., "A method for ferulic acid production from rice bran oil soapstock using a homogenous system," Applied sciences, vol. 7, no. 8, p. 796, 2017.

[17] A. Tuulmets and S. Salmar, "Effect of ultrasound on ester hydrolysis in aqueous ethanol," Ultrasonics Sonochemistry, vol. 8, no. 3, pp. 209-212, 2001.

[18] A. Tuulmets and P. Raik, "Ultrasonic acceleration of ester hydrolyses," Ultrasonics Sonochemistry, vol. 6, no. 1-2, pp. 85-87, 1999.

[19] A. Tuulmets, "Ultrasound and polar homogeneous reactions," Ultrasonics Sonochemistry, vol. 4, no. 2, pp. 189-193, 1997.

[20] A. K. Nanda and M. M. Sharma, "Kinetics of fast alkaline hydrolysis of esters," Chemical Engineering Science, vol. 22, no. 5, pp. 769-775, 1967.

[21] S. Piiskop, S. Salmar, A. Tuulmets, A. Kuznetsov, and J. Järv, "Kinetic sonication effects in aqueous acetonitrile solutions. Reaction rate levelling by ultrasound," Ultrasonics Sonochemistry, vol. 20, no. 6, pp. 1414-1418, 2013.

[22] A. Tuulmets, G. Cravotto, S. Salmar, and J. Jarv, "Sonochemistry of homogeneous ionic reactions," Mini-Reviews in Organic Chemistry, vol. 7, no. 3, pp. 204-211, 2010.

[23] T. J. Mason, J. P. Lorimer, and B. P. Mistry, "The effect of ultrasound on the solvolysis of 2-chloro-2-methylpropane in aqueous alcoholic media," Tetrahedron Letters, vol. 23, no. 50, pp. 5363-5364, 1982.

[24] J. P. Lorimer, T. J. Mason, and B. P. Mistry, "Effect of ultrasound on the solvolysis of 2-chloro-2-methylpropane in aqueous alcoholic solvents," Ultrasonics, vol. 25, no. 1, pp. 23-28, 1987.

[25] T. J. Mason, J. P. Lorimer, and B. P. Mistry, "The effect of ultrasound on the solvolysis of 2-chloro-2-methylpropane in aqueous ethanol," Tetrahedron, vol. 41, no. 22, pp. 5201-5204, 1985.

[26] B. Dayal, G. Salen, B. Toome, G. S. Tint, S. Shefer, and J. J. Padia, "Lithium hydroxide/aqueous methanol: mild reagent for the hydrolysis of bile acid methyl esters," Steroids, vol. 55, no. 5, pp. 233-237, 1990.

[27] Z. Wang, C. Wang, C. Zhang, and W. Li, "Ultrasound-assisted enzyme catalyzed hydrolysis of olive waste and recovery of antioxidant phenolic compounds," Innovative Food Science \& Emerging Technologies, vol. 44, pp. 224-234, 2017.

[28] Vancouver Island University, Hydrolysis of a Carboxylic Acid Ester: Neutral and Base Enhanced Reaction of p-NitrophenylAcetate. Chemistry 331: Laboratory Manual, in Environmental Organic Chemistry, Vancouver Island University, Nanaimo, BC, Canada, 2006.

[29] J. M. Khurana, S. Chauhan, and G. Geeti Bansal, "Facial hydrolysis of esters with $\mathrm{KOH}-$ Methanol at ambient temperature," Monatshefte fur Chemie, vol. 135, no. 1, pp. 83-87, 2004.

[30] Y. Maeda, L. T. Thanh, K. Imamura et al., "New technology for the production of biodiesel fuel," Green Chemistry, vol. 13, no. 5, pp. 1124-1128, 2011.

[31] H. M. Santos, C. Lodeiro, and J.-L. Capelo-Martínez, "The power of ultrasound," in Ultrasound in Chemistry, pp. 1-16, 
Wiley-VCH Verlag GmbH \& Co. KGaA, Weinheim, Germany, 2009.

[32] M. Sivakumar, P. Senthilkumar, S. Majumdar, and A. B. Pandit, "Ultrasound mediated alkaline hydrolysis of methyl benzoate-reinvestigation with crucial parameters," Ultrasonics Sonochemistry, vol. 9, no. 1, pp. 25-30, 2002.

[33] A. Abulizi, K. Okitsu, and J.-J. Zhu, "Ultrasound assisted reduction of graphene oxide to graphene in l-ascorbic acid aqueous solutions: kinetics and effects of various factors on the rate of graphene formation," Ultrasonics Sonochemistry, vol. 21 , no. 3 , pp. 1174-1181, 2014. 

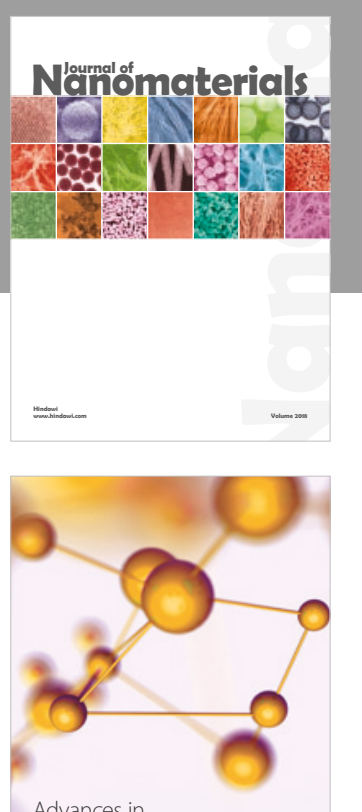

Physical Chemistry
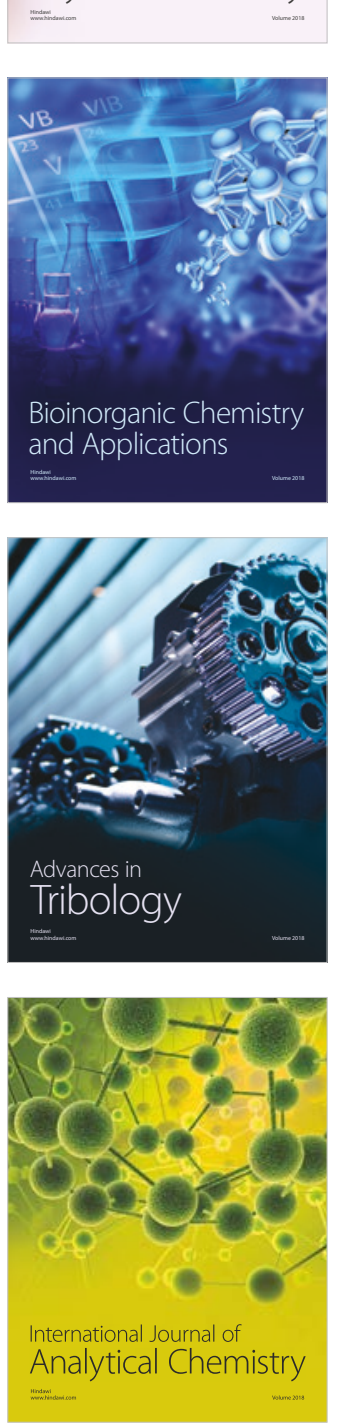

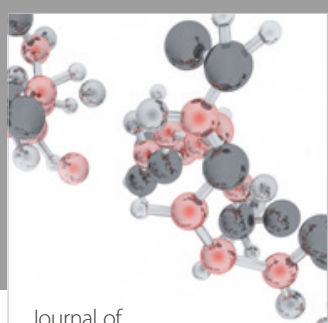

Analytical Methods

in Chemistry

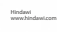

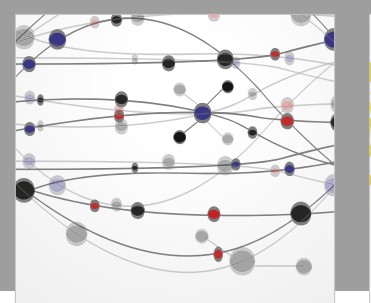

The Scientific World Journal

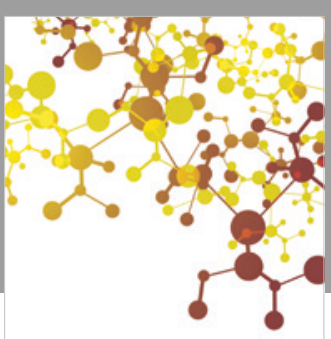

Journal of

Applied Chemistry
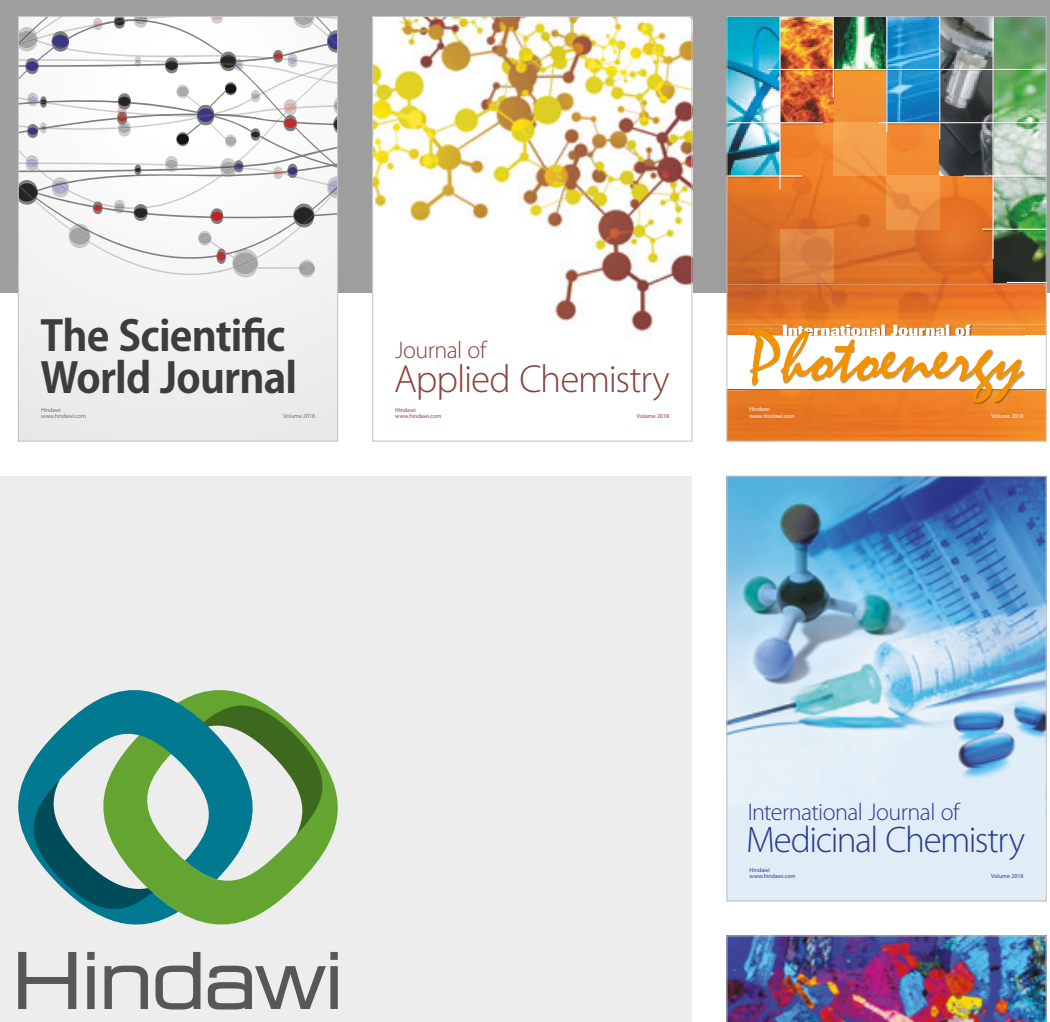

Submit your manuscripts at

www.hindawi.com
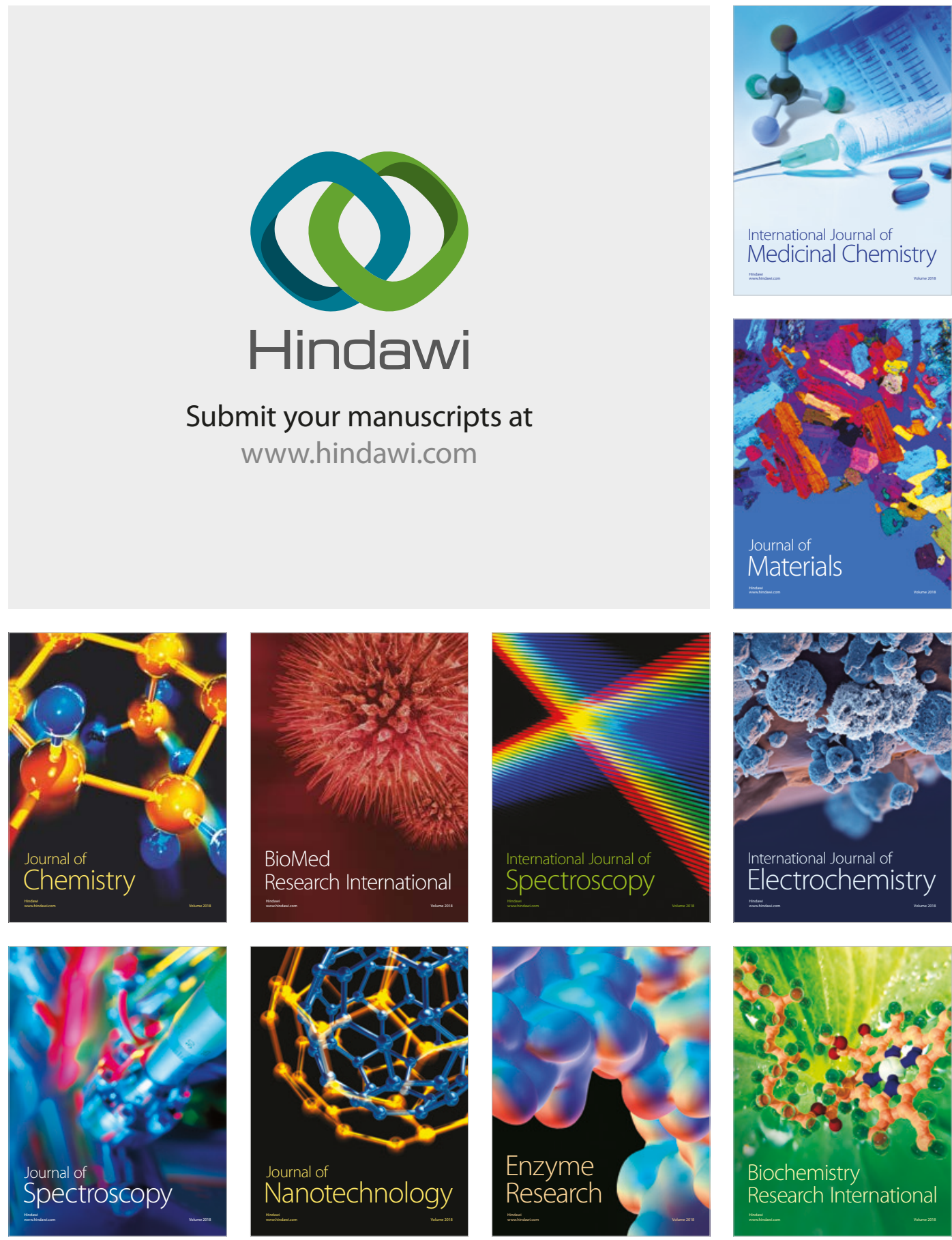
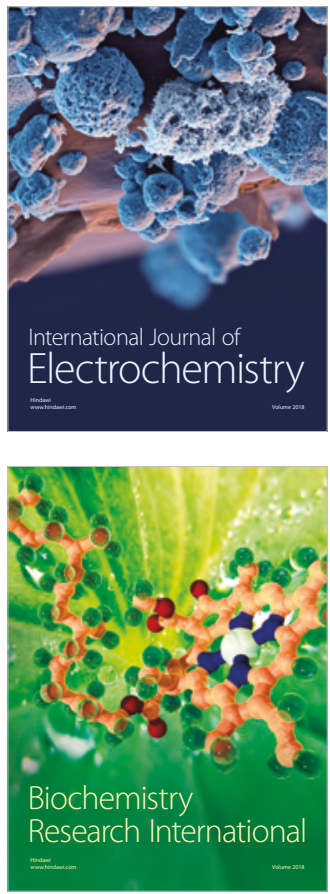